\title{
Study on Pressure Relief and Outburst Prevention Technology of Deep Coal Roadway Strip
}

\author{
Jianjun CAO \\ China Coal Technology Engineering Group Chongqing Research Institute, Chongqing, China \\ Anhui University of Science and Technology, Huainan, China \\ National Key Laboratory of Gas Disaster Detecting, Preventing and Emergency Controlling, Chongqing, China \\ e-mail: caojianjun207@126.com
}

\begin{abstract}
Based on the mechanism of composite energy and its energy scale, evolution and distribution law of stress and fracture field in surrounding rock of roadway in deep mining, the article puts forward regional outburst prevention measures of unloading pressure by pre excavation rock roadway and constructing wear layer drilling to pump coal roadway strip gas, a complete set of technical system of regional outburst prevention in coal roadway strip by pre excavation and unloading floor roadway in the Fengcheng mining area is obtained. The field practice shows that regional outburst prevention in coal roadway strip is carried through pre excavation of floor roadway which layout in the bottom of the bottom of the coal roadway $8 \sim 12 \mathrm{~m}$ to carry on the pressure relief combined with wear layer drilling drainage gas, it can greatly improve the permeability of coal seam and the effect of pressure relief, and ensure the safe and fast roadway excavation.
\end{abstract}

Keywords-stress dominated outburst; pressure relief bottom roadway; wear layer drilling; relieved drainage

\section{FOREWORD}

The mechanism of coal and gas outburst in deep mining is more complicated, with governance difficulty increased; the basic theory research cannot meet the actual needs of the project. Therefore, the mine outburst and other dynamic disasters along with the increase of mining depth, the change of mining conditions need to constantly understand and study the new countermeasures.

The general trend of coal and gas dynamic disaster prevention and control is based on the main control factors of the risk sources, the primary and secondary relationships of in-situ stress and gas, and then take the comprehensive technical measures for pressure relief, control energy, gas drainage, induced by the change of coal and rock dynamic tendency and the physical and mechanical properties.

China's current laws and regulations are not allowed to implement the regional outburst prevention measures in the face of serious outburst coal seam [1-3]. Therefore, a single serious outburst coal seam in the area to prevent the outburst adopt the pre excavation unloading pressure floor rock roadway drilling drainage gas outburst prevention which is a widely used in the area of prevention and control measures.

\section{MECHANISM OF COAL AND GAS DYNAMIC DISASTER IN DEEP COAL MINE AND TECHNICAL PRINCIPLE OF PRESSURE RELIEF AND OUTBURST PREVENTION IN COAL ROADWAY}

\section{A. Mechanical Mechanism of Outburst in Deep Coal Roadway}

The energy transmitted in the outburst of the coal roadway is mainly in coal and rock elastic energy, internal energy of gas, coal and gas outburst, thrown out when the kinetic energy of the progressive failure process of coal rock (steady damage but not thrown) the energy required, the unified energy expression of coal and rock dynamic disasters is [4-7]:

$$
\mathrm{E}_{\text {surrounding rock }}+E_{\text {coal }}+E_{\text {gas }}+E_{\text {outside }}=E_{\mathrm{p}}+E_{\mathrm{r}}
$$

In the formula: $E_{\mathrm{p}}$ is the energy required for progressive failure of coal and rock (stable damage but not thrown); $E_{\mathrm{r}}$ is the energy required to destroy the coal and rock.

The energy stored in coal and rock gas dynamic disaster is mainly the elastic potential energy of gas and coal. Slow release of gas do not work on coal and gas outburst, only when the coal is subjected to severe fragmentation, the exposed surface of coal increases rapidly, and the gas in the coal can be quickly released and expanded, and the gas can be released quickly, which is the main energy source for the occurrence and development of the disaster; In the same way, the rapid release of the elastic potential of coal and rock can cause the rapid destruction of the coal body. Therefore, the failure of the coal and rock system must consider the time effect. Under the conditions of the external trigger, the energy released by the coal and rock mass at the critical state in the unit time is greater than the energy required to break it in a progressive form, the excess energy will cause instability and destruction of coal rock, and it often has the characteristics of sudden destruction. 
B. The Principle of Pressure Relief and Outburst Prevention by Pre Excavation Floor Rock Roadway

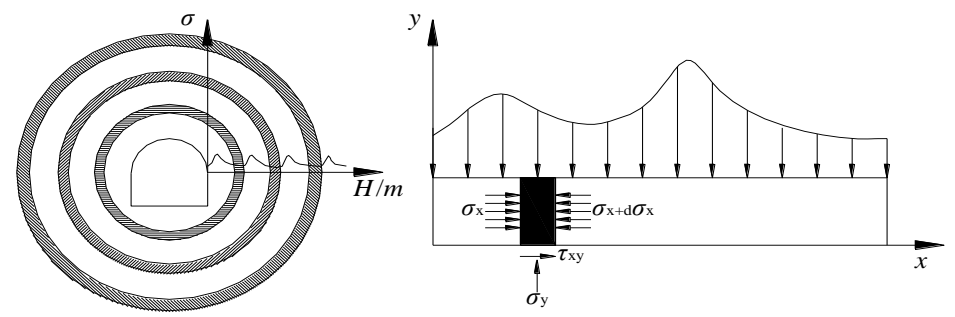

Figure 1. Schematic diagram of non peak stress distribution in partition failure of roadway surrounding rock

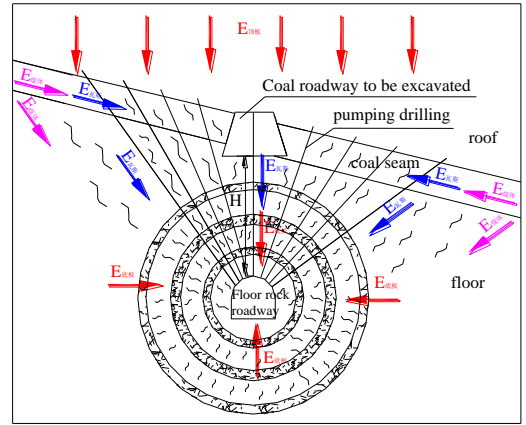

Figure 2. Pressure relief principle of wear layer pumping drilling in pre driving floor rock roadway

The coal and rock mass in the deep high stress environment is in the post peak characteristic state, there may be complex stress zone in roadway surrounding rock, the state of roadway surrounding rock under certain conditions sometimes occur the case of alternating between the expansion and compression zones, and the geometric size (width) by a geometric series increase, and it will appear the phenomenon of regional breakdown; The peak of roadway surrounding rock stress is weakened, and the width of pressure relief zone increases significantly, as shown in Figure $1[8]$.

In the deep tunnel, there are a number of rupture zones, the surface of the roadway to the outside boundary of the most lateral rupture area, which is the pressure relief radius of the roadway. Assuming the most lateral rupture zone is i, the expression of the inner and outer boundary of the rupture zone is:

$$
\begin{aligned}
& R_{i}^{i}=R_{i-1}^{e} \times\left[\frac{v(3-2 v)(1+v) p_{0}+(1-v) \sigma_{t}}{\left(p_{i-1}^{e}-\sigma_{t}\right)(1-v)^{2}}\right]^{\frac{1-\sin \varphi}{2 \sin \varphi}} \\
& R_{i}^{e}=R_{i}^{i} \times\left[\frac{3}{-12(3-2 v)\left(1-v^{2}\right) \sigma_{i} / p_{0}-v^{2}(2 v-1)^{2}}\right]^{\frac{1}{4}}
\end{aligned}
$$

The index of $R$ and $P$ indicates the number of the rupture zone; $i$ represents the inner boundary of the rupture zone; $e$ represents the outer boundary of the rupture zone; $v$ represents material Poisson's ratio; $P$ is the original rock stress.

To sum up, because of the large difference between shallow mining and deep mining in the mining area, there is a difference in the width of the unloading zone around the roadway surrounding rock. In the deep mining, the stress level is higher, and there may be a zonal disintegration phenomenon in the vicinity of the surrounding rock, and the width of pressure relief zone increases obviously.

Based on the elastic and plastic rheological properties of floor roadway surrounding rock stress, selecting the appropriate location in the bottom plate of the coal roadway that to be excavated, unloading pressure by pre excavation rock roadway, The elastic properties of coal seam and roof and floor are released in advance, and the permeability and the hardness of coal in the coal lane to be excavated are increased; Using the bottom plate rock roadway unloading pressure or the construction of wear layer drilling for relieved drainage coal roadway strip gas, then it can eliminate or reduce the elastic energy and gas potential in the process of coal roadway driving, so as to realize the purpose of regional outburst prevention in coal roadway strip, as shown in figure 2.

\section{ANALYSIS ON THE EFFECT OF REGIONAL OUTBURST PREVENTION MEASURES THROUGH STRIP RELIEVED DRAINAGE IN COAL ROADWAY}

\section{A. Standard Effect of Coal Roadway Strip Pumping}

The testing roadway adopts the way of pre pumping strip gas of coal roadway to be excavated to carry out the regional outburst prevention, drainage effect of statistical analysis are shown in Table 1 [9]. 
Table 1 shows, Qujiang, Shangzhuang, Jianxin 3 mine in Fengcheng mining area, there are 5 coal roadway outburst prevention measures by the combination of floor roadway pressure relief and gas pumping, the pumping effect is significant after floor roadway pressure relief, the highest gas pumping rate is $32 \% \sim 58 \%$, the residual gas content is approaching $2.67 \sim 5.48 \mathrm{~m}^{3} / \mathrm{t}$ after the pumping of $86 \sim 135 \mathrm{~d}$, far lower than that of $8 \mathrm{~m} 3 / \mathrm{t}$, it realizes the outburst of coal roadway in the coal mining area, which provides a guarantee for the safety of coal roadway.

\section{B. Verification of Outburst Prevention Effect in Coal Roadway}

After the effective test of regional outburst prevention measures in testing roadway, the tunneling verification was carried out for coal roadway to be excavated, and the local outburst danger in the process of coal roadway driving was predicted.

Shangzhuang mine 710 and 505 crossheading after taking outburst prevention measures by the combination of floor roadway pressure relief and gas pumping, local outburst risk prediction indices were small, the $K_{1}$ value of gas desorption index of drilling cuttings is between $0.08 \sim 0.43 \mathrm{ml} / \mathrm{g} \cdot \mathrm{min}^{1 / 2}$, the $S$ value of drilling cuttings content is between $2 \sim 4.7 \mathrm{~kg} / \mathrm{m}$, these are less than the critical value $0.5 \mathrm{ml} / \mathrm{g} \cdot \mathrm{min}^{1 / 2}$ and $6 \mathrm{~kg} / \mathrm{m}$, it realizes the safe and fast development of coal roadway.

Qujiang mine 702 and 213 crossheading after taking outburst prevention measures by the combination of floor roadway pressure relief and gas pumping, local outburst risk prediction indices were small, the $K_{1}$ value of gas desorption index of drilling cuttings is between $0.08 \sim 0.65 \mathrm{ml} / \mathrm{g} \cdot \mathrm{min}^{1 / 2}$, the $S$ value of drilling cuttings content is between $2 \sim 4.2 \mathrm{~kg} / \mathrm{m}$, these are less than the critical value $0.7 \mathrm{ml} / \mathrm{g} \cdot \mathrm{min}^{1 / 2}$ and $6 \mathrm{~kg} / \mathrm{m}$, it realizes the safe and fast development of coal roadway.

Jianxin mine 1128 crossheading after taking outburst prevention measures by the combination of floor roadway pressure relief and gas pumping, local outburst risk prediction indices were small, the $K_{1}$ value of gas desorption index of drilling cuttings is between $0.11 \sim 0.45 \mathrm{ml} / \mathrm{g} \cdot \mathrm{min}^{1 / 2}$, it is less than the critical value $0.5 \mathrm{ml} / \mathrm{g} \cdot \mathrm{min}^{1 / 2}$, it realizes the safe and fast development of coal roadway.

TABLE I. Evaluation Form of Wear LAyer Drilling Pre Pumping EFFect

\begin{tabular}{|c|c|c|c|c|c|c|c|c|}
\hline \multirow{2}{*}{ Roadway } & \multirow{2}{*}{$\begin{array}{l}\text { Judge } \\
\text { times }\end{array}$} & \multirow{2}{*}{$\begin{array}{c}\text { Judge } \\
\text { length } \\
\text { /m }\end{array}$} & \multirow{2}{*}{$\begin{array}{c}\text { Gas } \\
\text { pumping } \\
\text { volume } \\
/ \mathbf{m}^{3}\end{array}$} & \multicolumn{2}{|c|}{ Effect inspection } & \multirow{2}{*}{$\begin{array}{c}\text { Pumping } \\
\text { rate } \\
1 \%\end{array}$} & \multirow{2}{*}{$\begin{array}{c}\text { Pumping } \\
\text { time } \\
/ d\end{array}$} & \multirow{2}{*}{$\begin{array}{l}\text { Pumping } \\
\text { effect }\end{array}$} \\
\hline & & & & Number & $\begin{array}{c}\text { Gas content } \\
/ \mathrm{m}^{3} / \mathrm{t}\end{array}$ & & & \\
\hline \multirow{2}{*}{$\begin{array}{l}\text { Shangzhuang mine } \\
710 \text { crossheading }\end{array}$} & 1 & 145 & 47514 & 3 & $3.24 \sim 4.05$ & 36 & 121 & Standard \\
\hline & 2 & 95 & 36438 & 3 & $2.67 \sim 4.33$ & 35 & 109 & Standard \\
\hline \multirow{3}{*}{$\begin{array}{l}\text { Shangzhuang mine } \\
505 \text { crossheading }\end{array}$} & 1 & 65 & 11731 & 2 & $3.75 \sim 4.82$ & 32 & 95 & Standard \\
\hline & 2 & 60 & 37967 & 3 & $2.98 \sim 5.02$ & 43 & 103 & Standard \\
\hline & 3 & 65 & 26056 & 3 & $3.14 \sim 5.48$ & 37 & 99 & Standard \\
\hline \multirow{3}{*}{$\begin{array}{l}\text { Qujiang mine } \\
702 \text { crossheading }\end{array}$} & 1 & 78 & 74397 & 2 & $3.44 \sim 4.12$ & 38 & 135 & Standard \\
\hline & 2 & 94 & 79256 & 2 & $3.07 \sim 4.23$ & 41 & 130 & Standard \\
\hline & 3 & 103 & 88657 & 4 & $2.99 \sim 4.86$ & 38 & 110 & Standard \\
\hline \multirow{3}{*}{$\begin{array}{l}\text { Qujiang mine } \\
213 \text { crossheading }\end{array}$} & 1 & 40 & 35753 & 2 & $3.08 \sim 4.24$ & 49 & 86 & Standard \\
\hline & 2 & 76 & 79792 & 3 & $3.17 \sim 4.29$ & 58 & 96 & Standard \\
\hline & 3 & 120 & 112488 & 4 & $3.77 \sim 4.92$ & 51 & 102 & Standard \\
\hline \multirow{2}{*}{$\begin{array}{c}\text { Jianxin mine } \\
1128 \text { crossheading }\end{array}$} & 1 & 164 & 65232 & 5 & $4.03 \sim 5.39$ & 40 & 91 & Standard \\
\hline & 2 & 345 & 173548 & 10 & $3.09 \sim 4.94$ & 47 & 81 & Standard \\
\hline
\end{tabular}




\section{MAIN CONCLUSION}

Based on the elastic plastic flow analysis of floor roadway surrounding rock, the stress is relatively low in the shallow mining area, and the radius of the loose circle of the surrounding rock is small; Under the conditions of high stress and high temperature, the surrounding rock of roadway may produce the zonal disintegration phenomenon, the radius of pressure relief circle of roadway surrounding rock is significantly increased, which is obviously larger than that of the shallow part.

In the serious outburst coal seam, selecting the appropriate location in the bottom of the roadway to be drived, through the coal roadway strip for pressure relief and gas pumping to realize the purpose of regional outburst prevention.

Coal roadway strip in test mine, regional outburst prevention is carried through pre excavation of floor roadway which layout in the bottom of the bottom of the coal roadway $8 \sim 12 \mathrm{~m}$ to carry on the pressure relief combined with wear layer drilling drainage gas, it can greatly improve the permeability of coal seam and the effect of pressure relief, and ensure the safe and fast roadway excavation.

\section{ACKNOWLEDGMENT}

This work was financially supported by the National Natural Science Foundation of China (51604298) and China Coal Technology Engineering Group Chongqing Research
Institute of independent research and development project (2015YBXM39).

\section{REFERENCES}

[1] State Administration of Work Safety, State Administration of Coal Mine Safety. Coal mine safety regulation [M]. Beijing: China Coal Industry Publishing House, 2016.

[2] State Administration of Work Safety, State Administration of Coal Mine Safety. Provisions on prevention of coal and gas outburst [M]. Beijing: China Coal Industry Publishing House, 2009.

[3] State Administration of Work Safety, National Development and Reform Commission, National Energy Administration, et al. Provisional Regulations of coal mine gas pumping [S]. Beijing: China Coal Industry Publishing House, 2012.

[4] Qianting Hu, Guangcai Wen. Mechanicalaction mechanism of coal and gas outburst [M]. Beijing: Science Press, 2013.

[5] Da Huang. Study on unloading deformation mechanism and stability of excavating surrounding rock mass of large underground caverns [D]. Chengdu: Chengdu University of Technology [D], 2007.

[6] Yanguang Chen, Shiliang Lu. Surrounding rock control of coal mine roadway in China $[\mathrm{M}]$. Xuzhou: Publishing House of China University of Mining and Technology, 1994.

[7] Heping Xie, Ruidong Peng, Yang Ju. Energy dissipation analysis in the process of deformation and failure of rock [J]. Chinese Journal of rock mechanics and engineering, 2004, 23(21):3565-3570.

[8] Gao Liu. Study on stability of surrounding rock stability in high stress area [D]. Chengdu: Chengdu University of Technology, 2001.

[9] Xianzheng Meng, Zhonghua Wang, Guohong Chen, et al. Study on pressure relief and outburst prevention technology of coal roadway in deep single serious outburst coal seam [R]. Chongqing: China Coal Technology Engineering Group Chongqing Research Institute, 2014. 